\title{
Skeletal progenitors and the GNAS gene: fibrous dysplasia of bone read through stem cells
}

\author{
Mara Riminucci $^{1,2}$, Pamela Gehron Robey ${ }^{3}$, Isabella Saggio ${ }^{2,4}$ and Paolo Bianco ${ }^{1,2}$ \\ ${ }^{1}$ Department of Molecular Medicine, La Sapienza University, 00161 Rome, Italy \\ ${ }^{2}$ Biomedical Science Park San Raffaele, 00128 Rome, Italy \\ ${ }^{3}$ Department of Health and Human Services, Craniofacial and Skeletal Diseases Branch, National Institute of Dental and Craniofacial Research, \\ National Institutes of Health, Bethesda, Maryland 20892, USA \\ ${ }^{4}$ Department of Genetics and Molecular Biology, Sapienza University of Rome, and Institute for Molecular Biology and Pathology, \\ National Research Council (CNR), 00185 Rome, Italy \\ (Correspondence should be addressed to P Bianco who is now at Division of Pathology, Department of Molecular Medicine, Sapienza University of Rome, \\ Viale Regina Elena 324, 00161 Rome, Italy; Email: paolo.bianco@uniroma1.it)
}

\begin{abstract}
Activating mutations of the GNAS gene, which causes fibrous dysplasia of bone (FD), lead to remarkable changes in the properties of skeletal progenitors, and it is these changes that mediate the pathological effect of this gene on bone. Mutated skeletal stem cells lose the ability to differentiate into adipocytes, and to maintain in situ, and transfer heterotopically, the hematopoietic microenvironment, leading to abnormal bone marrow histology in FD. They overexpress molecular effectors of osteoclastogenesis, thus promoting inappropriate bone resorption leading to fragility of FD bone. They express the phosphate-regulating hormone FGF-23 at normal levels, whose excess in the serum of FD patients correlates with the mass of osteogenic cells within FD lesions, leading to osteomalacia and deformity of the FD bone, and revealing that bone is an endocrine organ regulating renal handling of phosphate. Mechanisms of allelic selection and stem cell selection occur in mutated skeletal stem cells and contribute to the inherent diversity and evolution over time in FD. The definition of the etiological role of GNAS mutations marks the watershed between many decades of descriptive observation and the definition of cellular and molecular mechanisms that would explain and hopefully allow for a cure for the disease. Placing stem cells at center stage has permitted substantial advances in one decade, and promises more for the one to come.
\end{abstract}

Journal of Molecular Endocrinology (2010) 45, 355-364

\section{Skeletal stem cells and bone disease}

The notion that the human bone marrow includes a second type of stem cell besides hematopoietic stem cells originates from classical studies demonstrating an inherent osteogenic potential of boneless marrow fragments transplanted heterotopically (Tavassoli \& Crosby 1968). This potential was later ascribed to adherent, non-hematopoietic, stromal cells, noted for their ability to initiate density-insensitive clonal growth of 'fibroblastic' colonies (Friedenstein et al. 1970, 1974). The idea that these colony forming unitfibroblasts (CFU-Fs) would include a subset of putative stem cells was substantiated by the observation that the clonal progeny of a single CFU-F could generate multiple differentiated tissues normally found in the skeleton, i.e. cartilage, bone, hematopoietic supportive stroma, fibrous tissues, and adipocytes. Hence, the hypothesis of a 'osteogenic' (Friedenstein et al. 1987) or 'stromal' (Owen \& Friedenstein 1988) stem cell was formulated, and later resonated in the rediscovery of the 'osteogenic' cells as 'mesenchymal stem cells' (Caplan 1991, Pittenger et al. 1999). Skeletal stem cells (Bianco \& Robey 2004, Bianco et al. 2006, 2008) are found in the wall of bone marrow sinusoids (Sacchetti et al. 2007), where they reside as adventitial reticular cells, a bone marrow-specific adaptation of the 'mural cell'/pericyte phenotype found in the microvascular wall of all tissues (Bianco et al. 2008). They can be prospectively isolated based on expression of CD146/MCAM (Sacchetti et al. 2007), a cell adhesion molecule of the immunoglobulin superfamily expressed in adventitial reticular cells in the bone marrow and in pericytes in other tissues. Immunoselection for CD146 allows for isolation of the CFU-Fs, which therefore correspond to CD146-expressing cells in the intact bone marrow, and thus to adventitial reticular cells. In vivo, adventitial reticular cells can generate adipocytes (Bianco et al. 1988) and bone, and provide structural and functional support to hematopoietic 
progenitors in vivo (Weiss 1976, Westen \& Bainton 1979). Upon isolation as CFU-Fs and growth in culture, they generate a progeny of stromal cells that can be heterotopically transplanted in immunocompromised hosts. Heterotopic 'ossicles' are thus generated, in which the hematopoietic microenvironment is established (Fig. 1A). During the development of heterotopic ossicles, a subset of transplanted cells self-renew into adventitial reticular cells of the newly formed bone marrow sinusoids, and reconstitute a compartment of CFU-Fs that can be secondarily passaged as CD146expressing clonogenic progenitors (Sacchetti et al. 2007). Heterotopic ossicles are chimeric systems in which bone and the hematopoietic stroma are of donor origin, while hematopoietic cells and endothelial cells are of host origin. They represent the defining evidence of both potency and self-renewal of skeletal stem cells.

A role for bone marrow stromal cells as mediators/ effectors of disease of bone and bone marrow was long surmised in a variety of conditions including idiopathic myelofibrosis, hyperparathyroid bone disease, and bone metastasis. Their inherent ability to generate bone (as illustrated by ex vivo explantation and in vivo transplantation studies) was easily linked, conceptually, to the establishment of heterotopic bone, and stromal changes within the bone marrow space are some of these natural pathological conditions in humans. This had become the proper scenario in which the analysis of a genetic bone disease at the stem cell level was inscribed.

\section{The GNAS gene}

Human GNAS is an imprinted gene locus, located on chromosome 20q13, within which several transcripts and alternative isoforms are encoded (Rao et al. 1991, Kehlenbach et al. 1994, Hayward et al. 1998a). The major GNAS transcripts, such as Gs- $\alpha$, XLas, NESP, and 1A (alternatively termed A/B), are generated from transcript-specific promoters and first exons and share

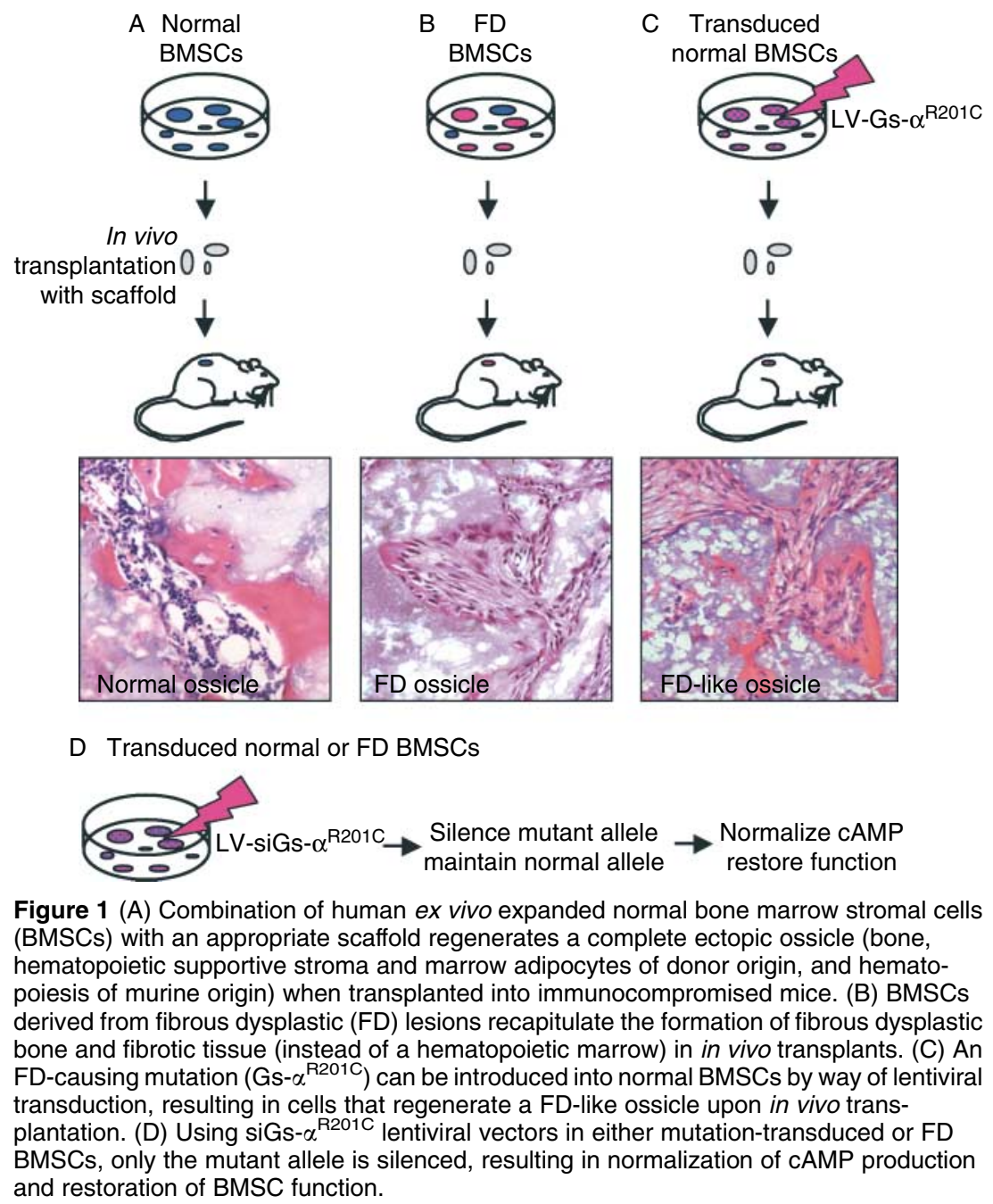




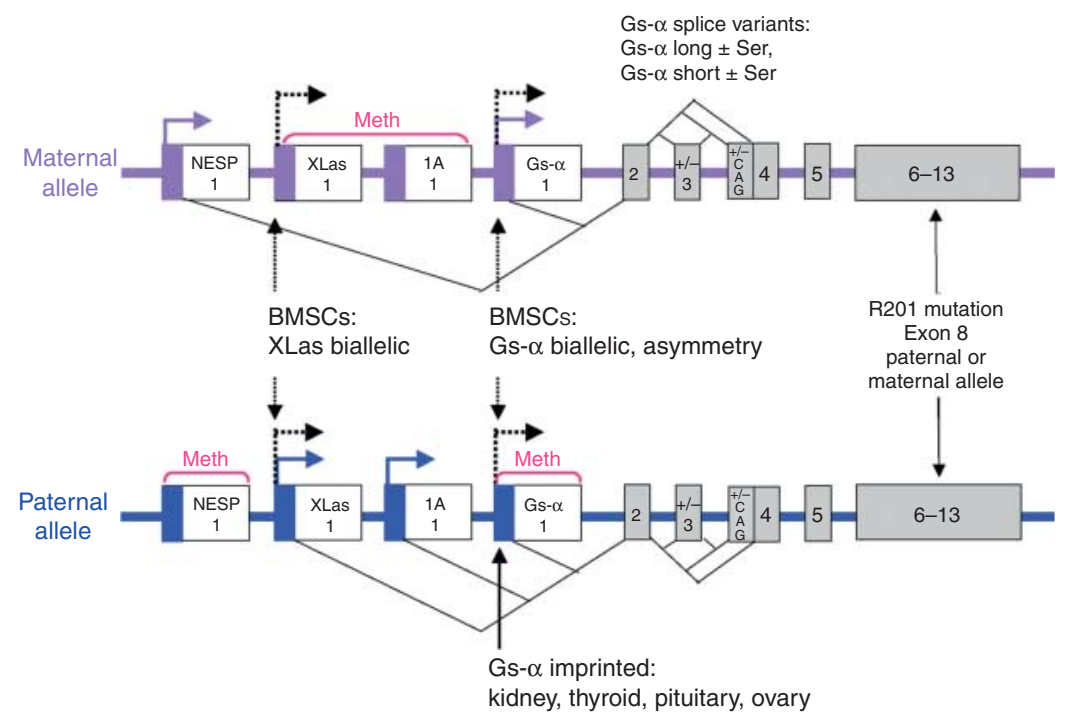

Figure 2 The GNAS chromosomal region showing promoters (solid boxes) and first exons specific for each transcript (NESP55, XLas, 1A, and Gs- $\alpha$ ) as white boxes and exons common to all GNAS transcripts as gray boxes (exons 2-13). NESP55 is expressed from the maternal allele (purple), whereas XLas and $1 \mathrm{~A}$ are expressed from the paternal allele (blue) due to methylation patterns (meth). In clonogenic bone marrow stromal cells (BMSCs) derived from either normal or FD tissue, NESP is restricted to a subset of clonal cells and is expressed from the maternal allele. However, unlike in other tissues, XLas is expressed from both the maternal and paternal alleles in normal and FD BMSCs (dashed arrows). Gs- $\alpha$ is expressed from both alleles in most (but not all) normal tissues and four different splice variants has been reported: Gs- $\alpha-1$ (long, with exon 3 ), Gs- $\alpha-2$ (short, without exon 3 ), Gs- $\alpha-3$ (long form with CAG immediately upstream of exon 4) (codon CAG), and Gs- $\alpha-4$ (short form with CAG). The R201 FD mutation site is in exon 8 . In kidney, thyroid, pituitary, and ovary tissues, Gs- $\alpha$ is only expressed from the paternal allele (black arrow), but in normal and FD BMSCs, overall, it is expressed from both alleles (dashed arrows), although a great deal of asymmetry of expression is noted in clonal BMSC strains.

a common downstream sequence (Fig. 2). The XLas transcript is expressed in neuroendocrine cells and, to a lesser extent, in other tissues and cell types such as brain, pancreas, adrenal gland, heart, kidney, adipose tissues, and osteogenic cells (Pasolli et al. 2000, Plagge et al. 2004, Michienzi et al. 2007). XLas protein shares with Gs- $\alpha$ the entire carboxyl-terminal region (Kehlenbach et al. 1994), and displays some Gs- $\alpha$-like properties in vitro (Klemke et al. 2000, Bastepe et al. 2002, Linglart et al. 2006). NESP expression is highly restricted to neuroendocrine tissues in which the transcript is translated into a chromogranin-like protein, NESP55. The NESP-coding sequence is limited to the first exon, and the resulting protein is unrelated to either Gs- $\alpha$ or XLas (Ischia et al. 1997). 1A mRNA is ubiquitously expressed. However, it is not translated into a functional protein, and its function remains as yet unclear. In addition to Gs- $\alpha$, NESP, XLas, $1 \mathrm{~A}$, and splice variants thereof, other less well-known GNAS transcripts, such as an antisense transcript, NESPAS, and others (Wroe et al. 2000, Holmes et al. 2003), have been identified, which add further complexity to the locus (Klemke et al. 2001, Freson et al. 2003).
The expression of GNAS products is epigenetically regulated according to a complex pattern of imprinting (Reik \& Walter 2001; Fig. 2). XLas and 1A are paternally transcribed, and their promoters are methylated on the maternal allele. In contrast, the origin of NESP is exclusively maternal, and its promoter is methylated on the paternal allele (Hayward et al. 1998a,b, Peters et al. 1999). The Gs- $\alpha$ promoter is unmethylated on both alleles. However, recent studies identified an imprinting mark around the 1A promoter, which is thought to suppress the expression of Gs- $\alpha$ from the paternal allele in a tissue-specific manner (Liu et al. 2005). Partial imprinting of Gs- $\alpha$ has also been observed in the human renal proximal tubule, anterior pituitary, and thyroid (Hayward et al. 2001, Germain-Lee et al. 2002, Mantovani et al. 2002), which has clinical implications in patients carrying loss-of-function mutations of GNAS.

Following transcription, each GNAS transcript is alternatively spliced to generate two isoforms (long and short), plus and minus exon 3 respectively. In addition, the serine residue at the end of exon 3 can be spliced in or out to generate a total of two long and two short variants (Fig. 2). Gs- $\alpha$ splicing isoforms have been 
the subject of multiple studies. The long and the short Gs- $\alpha$ mRNAs are translated into different molecular weight proteins, the distribution and relative ratio of which vary in different developmental and metabolic conditions (van der Vuurst et al. 1998, Ihnatovych et al. 2001, Frey et al. 2005). Whether the variants are functionally different remains to be determined (Kvapil et al. 1994, Novotny \& Svoboda 1998, Unson et al. 2000, Wenzel-Seifert et al. 2001).

\section{GNAS transcripts in skeletal progenitors}

Gs- $\alpha$ is expressed in all clonal strains established in culture from single osteoprogenitors, and in each clone, the Gs- $\alpha$ transcripts are spliced to generate comparable amounts of the four isoforms (plus and minus exon 3, plus and minus Ser). Although the specific function of the different Gs- $\alpha$ isoforms is currently unknown, their balanced expression could be a specific feature of undifferentiated skeletal progenitors. Indeed, our recent unpublished data demonstrate that the Gs- $\alpha$ long/short isoform ratio is dramatically reduced during osteogenic and adipocytic differentiation of skeletal progenitors in vitro.

In normal fetal and post-natal bone, as well as in fibrous dysplasia (FD) tissue, Gs- $\alpha$ transcripts are biallelic in origin, and the amount of the transcript generated from each allele is, overall, similar (Mantovani et al. 2004). In individual skeletal progenitors isolated in vitro, conversely, the transcriptional activity of the two Gs- $\alpha$ alleles may be significantly different (Michienzi et al. 2007). Each allele can be selectively expressed or conversely, almost completely, silenced in a random fashion, independent of parental origin of each allele (Fig. 2). This pattern of regulation of expression of the two Gs- $\alpha$ alleles has never been reported in other systems, and its mechanism remains to be elucidated. However, it can neither be referred to as imprinting, which specifically involves maternal or paternal genes (Constancia et al. 1998), nor be referred to as allelic expression imbalance, which is an inherited trait and therefore consistent in different cells from the same patient (Yan et al. 2002).

Of the other GNAS transcripts, XLas, 1A, and NESP are all expressed in skeletal progenitors, although the expression of NESP seems to be restricted to a small subset of clones. Interestingly, while NESP and 1A transcripts retain the monoallelic origin observed in other tissues, XLas displays, in cultured skeletal progenitors, a biallelic pattern of transcription, never previously reported in human cells (Michienzi et al. 2007; Fig. 2). In summary, the overall imprinting status of the gene in skeletal cells seems to be slightly different from that observed in other human tissues. In addition, multiple GNAS transcripts are expressed in skeletal stem cells and undifferentiated progenitors, but the GNAS transcript portfolio is remarkably heterogeneous among different clonogenic cells, even beyond the variable allelic origin of Gs- $\alpha$ itself. Further studies should elucidate how this complexity is modulated during differentiation events.

\section{Fibrous dysplasia of bone and GNAS mutations}

Activating missense mutation of the GNAS gene causes FD of bone (Weinstein et al. 1991, Schwindinger et al. 1992) (FD, OMIM 174800), and when more broadly distributed, a genetic, non-inherited multi-organ disease, which in addition to bone involves, in variable combination, a constellation of endocrine organs, the melanocyte system, the liver, and likely a broader range of tissues in which the clinical expression of the underlying mutation is either minor or not readily recognized (Bianco et al. 2003). The combination of FD, endocrinopathy, and skin pigmentation is classically known as the McCune-Albright syndrome (Albright et al. 1937, 1938), but additional syndromic pictures exist, such as Mazabraud's syndrome, in which FD combines with muscular myxomas (Henschen \& Fallvon 1926). Replacement of Arg201 with either His or Cys in the mutated protein results in a $\sim 30$-fold reduced intrinsic GTPase activity, translating into its constitutive activation (Bourne et al. 1989). Constitutively active Gs- $\alpha$ stimulates adenylyl cyclase, resulting in overproduction of cAMP and subsequent abnormal cellular responses.

Of the entire range of organ lesions, the skeletal lesions remain the most serious and the least treatable. Attention to skeletal stem cells and their role in the pathogenesis of FD was drawn by the observation that the fibrosis that characterizes the abnormal bone marrow of FD bone, like the one seen in hyperparathyroid bone disease, is in fact comprised of an excess of cells with phenotypic features of bone marrow stromal cells (Riminucci et al. 1997, 1999). GNASmutated CFU-Fs can indeed be isolated from the abnormal, fibrotic bone marrow of FD lesions, like normal CFU-Fs are isolated from normal bone marrow. It was then natural to reason that transplantation of mutated skeletal progenitors isolated from FD lesions would generate heterotopic ossicles recapitulating the abnormal histology of FD bone and fibrotic bone marrow, much like transplantation of normal skeletal progenitors recapitulates organogenesis of normal bone. Transplantation of bone marrow stromal cell strains derived from FD tissue generated FD-like ossicles, in which abnormal woven bone similar to FD bone is deposited by donor cells, and a fibrotic bone marrow develops, which like the fibrotic bone marrow 
of FD lesions does not accommodate hematopoietic cells, nor does it include bone marrow adipocytes (Bianco et al. 1998, 2000; Fig. 1B). Recapitulation of FD histology in ossicles generated by transplantation of mutated skeletal progenitors proved the principle of FD as a 'stem cell disease', and provided a humanized in vivo model of the disease based on stem cell transplantation.

\section{Skeletal progenitors as mediators of FD pathogenesis}

Mutated skeletal progenitors directly mediate specific facets of FD pathology. For example, greatly enhanced bone resorption noted in FD lesions is rooted into an enhanced osteoclastogenesis, mediated by osteogenic cells. Molecular mediators of these effects include IL6, which was shown to be produced in excess, and regulated by glucocorticoids, in bone marrow stromal cells isolated from FD lesions (Stanton et al. 1999). Both basal and induced production of IL6 appears to be different in clonal mutated skeletal progenitors compared to non-mutated cognates, and nonosteogenic cells within the local FD milieu can also contribute to local IL6 levels (Riminucci et al. 2003b). IL6 is also abundantly expressed in FD lesions in situ. Interestingly, FD lesions are noted for osteoclastogenic events that occur ectopically; i.e. within the fibrotic intertrabecular space and away from bone surfaces, and such ectopic osteoclastogenic foci were noted as sites of high expression of IL6 in stromal cells (Riminucci et al. 2003b). More recently, studies using lentiviral transduction of bone marrow stromal cells revealed a potent and rapid up-regulation of RANKL as one of the most prominent effects induced by mutated Gs- $\alpha$ (Piersanti et al. 2010), suggesting that direct interaction of mutated stromal cells with osteoclast progenitors may be involved in initiating osteoclastogenesis (and particularly, ectopic osteoclastogenesis) within FD lesions.

A crucial feature of FD lesions, directly linked to abnormal bone fragility and risk fracture, indeed represents the ultimate expression of a change in skeletal progenitors brought about by Gs- $\alpha$ mutation and excess cAMP production. Likewise, following sporadic reports on FD-associated osteomalacia (Ryan et al. 1968, Dent \& Gertner 1976, Dachille et al. 1990), systematic studies on the histopathology of FD demonstrated the occurrence of severe mineralization defects in the majority of FD lesions (Bianco et al. 2000, 2003, Corsi et al. 2003; Fig. 3A), and of generalized osteomalacia in a subset of patients. Attempts to elucidate the pathogenetic mechanisms of FD-associated osteomalacia identified the phosphaturic factor, FGF-23, as a major player in the disorder (Riminucci et al. 2003a, Kobayashi et al. 2006) and osteogenic cells as a major source of FGF-23 in the human body (Riminucci et al. 2003a; Fig. 3B). Inappropriate increases in serum FGF-23 levels cause a phosphate-wasting syndrome (reduced renal phosphate reabsorption, hypophosphatemia, and low levels of $\left.1,25-(\mathrm{OH})_{2}-\mathrm{D}_{3}\right)$ leading to rickets/osteomalacia, in a variety of settings (Shimada et al. 2001, Quarles 2003, Yu \& White 2005). In inherited hypophosphatemic rickets, increased serum levels of FGF-23 result either from missense mutations of the $F G F-23$ gene, which reduce the clearance of the protein (Autosomal dominant hypophosphatemic rickets, ADHR 2000), or from mutations of genes encoding other bone-derived factors such as Phex (X-linked hypophosphatemia (XLH; Jonsson et al. 2003)) and DMP-1 (autosomal recessive hypophosphatemic rickets, ARHR (Feng et al. 2006)) which, through as yet unknown mechanisms, regulate serum levels of FGF-23. In oncogenic osteomalacia, the phosphatewasting disorder is a paraneoplastic expression sustained by massive secretion of the molecule by mesenchymal neoplastic cells. Analysis of FGF-23 production in skeletal progenitors in situ (Fig. 3B) and in vitro leads to the recognition that increased FGF-23 in FD does not reflect a regulatory effect of GNAS on $F G F-23$ gene expression. Comparable levels of the molecule are produced in vitro, at the single cell level, by mutated FD cells and normal osteoprogenitors (Riminucci et al. 2003a), and serum levels of FGF-23 in FD patients therefore correlate with disease burden (Riminucci et al. 2003 $a$; Fig. 3C). Thus, in the range of bone and mineral disorders associated with excess FGF-23, the osteomalacia occurring in FD represents a unique type of phosphate-wasting syndrome emanating from the abnormal expansion of FGF-23-producing, non-neoplastic skeletal cells. On the other hand, the identification of production of FGF-23 by cells of osteogenic lineage including skeletal progenitors revealed the skeleton as an endocrine organ regulating renal handling of phosphate.

\section{Kinetics of GNAS-mutated stem cells in vivo}

Consumption of skeletal progenitors that occur over time in mice with targeted expression of a constitutively active PTH/PTHrP receptor (signaling through Gs- $\alpha$ ) in bone suggests that cAMP signaling might mediate a significant alteration in the population kinetics of skeletal progenitors. In as yet unknown mechanisms, activating GNAS mutations also seem to alter the stem cell-dependent kinetics of the osteogenic lineage in humans. FD and McCune-Albright syndrome (MAS) are somatic mosaic states, in which cells with either normal or disease genotypes coexist in different tissues and organs. Each clinical FD lesion consists itself of a mosaic of normal and mutated stem/progenitor cells, 

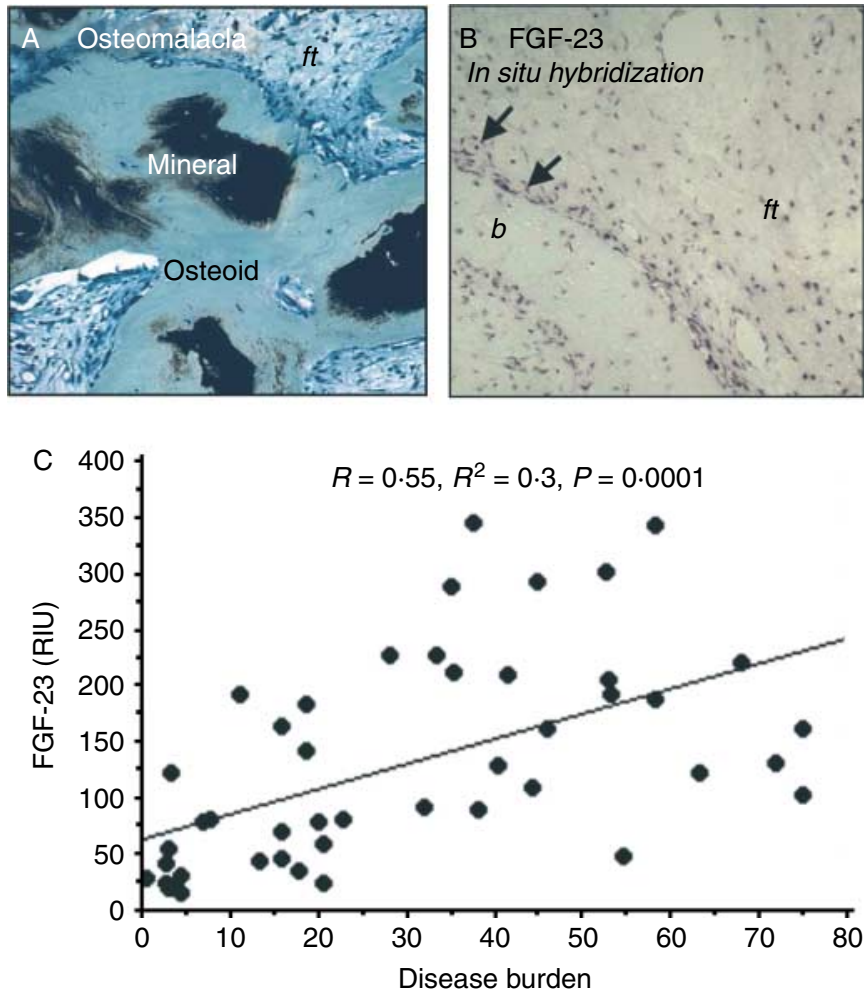

Figure 3 (A) Fibrous dysplastic bone is characterized by osteomalacia, as demonstrated by von Kossa staining that reveals poor mineralization and a great excess of osteoid material. (B) The osteomalacic nature of FD bone is caused by expression of the phosphate-regulating hormone, FGF-23, by misfunctioning osteoblastic cells (arrows) and cells in the fibrotic tissue (ft) within the lesions, as demonstrated by in situ hybridization. (C) While activating Gs- $\alpha$ mutations do not lead to an up-regulation of FGF-23, serum levels of FGF-23 correlated with disease burden, which reflects abundance of activated misfunctioning osteogenic cells and their precursors in fibrous dysplastic lesions.

rather than simply representing a uniformly mutated piece of a mosaic organism or organ (Bianco et al. 1998). Relative frequencies of normal and mutated stem/progenitor cells vary in individual lesions, patients, and in points of time in each patient (Kuznetsov et al. 2008; Fig. 4C). In a small cohort of patients, the frequency of mutated clonogenic stem/ progenitor cells appeared to be negatively correlated with patient's age (Fig. 4D), and was plausibly related to the high rate of apoptotic demise of osteogenic cells observed within FD lesions (Kuznetsov et al. 2008; Fig. 4A and B). At least in a proportion of 'aged' lesions observed past the age of skeletal maturity, mutated stem/progenitor cells are not detectable, and it is conceivable that this phenomenon reflects the ultimate clearance of mutated progenitors over time in some lesions. Interestingly, progressive remodeling of FD lesions into bone with normal architecture and clearance of fibrosis with restoration of hematopoietic marrow (Fig. 4E) also occur in a proportion of 'aged' FD lesions, in which mutated osteoprogenitors cannot be identified. Upon clearance of mutated CFU-Fs, nonclonogenic stromal cells carrying the disease genotype remain detectable within a lesional site. However, it is only in the presence of mutated stem/progenitor cells that bone marrow stromal cell strains recapitulate FD lesions upon xenotransplantation, suggesting that it is only retention of stem/progenitor cells that can maintain an FD lesion in vivo. Studies in larger cohorts of patients, specific analysis of the behavior of lesions at different skeletal sites (e.g. craniofacial versus appendicular), or with distinct overall histological patterns (Riminucci et al. 1999), and correlation with additional determinants of disease or of general hormonal status (e.g. excess of specific hormones, menopause, and gender) are needed to elucidate how these 'normalization' phenomena are inscribed into the general natural history of the disease. Clearly, lesions that keep 

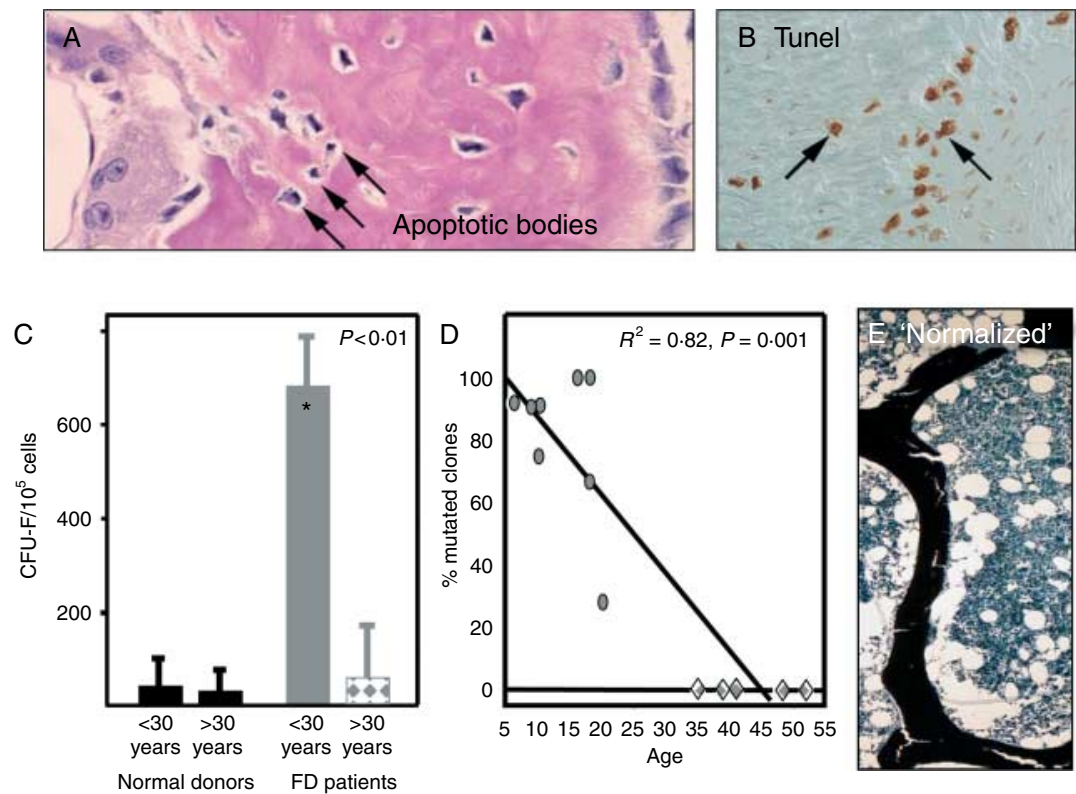

Figure 4 (A) In FD lesions obtained from young patients, a large number of apoptotic bodies are noted within the tissue (arrows). (B) Further evidence of apoptosis is demonstrated by TUNEL staining, suggesting extensive cell death within the lesions. (C) When the number of skeletal stem cells is estimated by determining the colony forming efficiency of normal and FD BMSCs, there is a huge increase in colony forming unitfibroblasts (CFU-Fs) from FD lesions compared to normal bone in patients under the age of 30; yet, the number decreases dramatically in patients over the age of 30 , and is not statistically different from normal, suggesting a biological change within the lesion.

(D) When the percent of mutant clones (arising from mutant CFU-Fs) was enumerated compared to normal clones, it was determined that there is a sharp decline as a function of age, with no mutant clones being identified in older patients, reflecting their demise due to apoptosis. (E) While mutant BMSCs are lost as a function of age, normal ones persist, and remodel lesional tissue into normal bone (stained black with von Kossa) and support the establishment of normal hematopoiesis.

progressing over the age of 40 are commonly seen clinically, and unfortunately FD cannot be seen as a selflimited disease in any way. Nonetheless, these 'normalization' events represent a striking example of stem cell replacement therapy in bone, brought about by nature itself. They remind us that stem cell therapy is feasible in $\mathrm{FD}$, as it is an option obviously chosen by nature itself. However, FD bone can only be replaced by normal bone, through stem cell-fueled remodeling, in a time window that extends over decades, due to the naturally low rate of turnover in bone. On a different note, it seems worth remarking, also, that remodeling of bone per se does not imply an adverse bearing on the evolution of FD lesions. In spite of its likely role in initiating and establishing the lesion, bone remodeling also has a role, at least in some cases, in reverting dysplastic bone back into normalized cancellous bone. Whereas current drug therapy remains anchored in the use of anti-remodeling agents, a more precise and focused understanding of the actual evolution of individual lesions at the time of pharmacological intervention might contribute to refine therapeutic choices and decisions.

\section{Transfer and analysis of the FD phenotype in stem cells}

Specific aspects of the role of GNAS mutation in dysregulating the biology of skeletal progenitors elude feasibility through study of FD-derived cells. Global analyses of transcriptome changes downstream of GNAS mutation, or elucidation of early responses induced in stem cells by GNAS mutations, are difficult, or impossible, respectively, using clinical material. The fundamental cellular phenotype can be transferred and reverted in stem cells using lentiviral technologies, which provide a complementary approach and circumvent these hurdles (Fig. 1C). The relevance of these strategies for analysis of the impact of GNAS mutations in stem cells rests with the controlled flexibility they allow in the exposure of stem cells to the disease gene. Thus, they allow for dissection of its early and late effects to match them to different differentiation stages, or to monitor cell responses, such as the induction of adaptive enhancement of phosphodiesterase activity and expression, in a controlled way. The same technologies, 
combined with strategies for allele-selective RNA interference, offer an option for attempting gene correction in skeletal stem cells (Fig. 1D). The idea of correcting a genetic disease in bone by correcting the underlying gene dysfunction in stem cells is both natural and supported by remarkable success histories in other areas of medicine and other kinds of stem cells (reviewed in Riminucci et al. (2006)). The FD-causing mutations are dominant, gain-of-function mutations in a gene that is otherwise indispensable and ubiquitously expressed. Silencing the disease gene is required, rather than gene replacement. Silencing must be specific for the mutated allele, as Gs- $\alpha$ function is indispensable, and the mutated allele only differs from the wild type by 1 base. This posits the most complex scenario one can conceive for gene therapy. Nonetheless, proof of principle for the feasibility of gene correction in FD has been provided. Expression of short hairpin RNA-interfering sequences through lentiviral vectors in human skeletal stem cells that are either derived from natural FD lesions, or transduced with lentiviral construct encoding the causative mutated Gs- $\alpha$, results in the loss of mutated Gs- $\alpha$ and in the abrogation of cAMP overproduction (Piersanti et al. 2010; Fig. 1D). As directed from lentiviral vectors, silencing is stable, and can be made completely specific for the mutated Gs- $\alpha$, leaving expression of the wildtype allele unscathed. In addition, the block of adipogenesis induced by mutated Gs- $\alpha$ in skeletal progenitors is reversed by lentiviral-directed, mutation-specific RNAi, indicating that at least some functional effects that specifically relate to the progenitor cell nature of the target cells (adipogenesis) downstream not only of the mutation per se, but also of the fundamental cellular phenotype (cAMP overproduction) can indeed be reverted at least in vitro.

\section{Declaration of interest}

The authors declare that there is no conflict of interest that could be perceived as prejudicing the impartiality of the research reported.

\section{Funding}

The authors' work mentioned in this article was funded by Telethon GGP09227, Fondazione Roma, and Ministry for University and Research of Italy.

\section{References}

Albright F, Butler AM, Hampton AO \& Smith P 1937 Syndrome characterized by osteitis fibrosa disseminata, areas of pigmentation and endocrine dysfunction with precocious puberty in females. New England Journal of Medicine 216 727-746. (doi:10.1056/

NEJM193704292161701)
Albright F, Scoville B \& Sulkowitch HW 1938 Syndrome characterized by osteitis fibrosa disseminata, areas of pigmentation, and a gonadal dysfunction: further observations including the report of two more cases. Endocrinology 22 411-421. (doi:10.1210/endo-22-4-411)

Autosomal dominant hypophosphataemic rickets consortium 2000 Autosomal dominant hypophosphataemic rickets is associated with mutations in FGF23. Nature Genetics 26 345-348. (doi:10.1038/ 81664)

Bastepe M, Gunes Y, Perez-Villamil B, Hunzelman J, Weinstein LS \& Juppner H 2002 Receptor-mediated adenylyl cyclase activation through XLalpha(s), the extra-large variant of the stimulatory G protein alpha-subunit. Molecular Endocrinology 16 1912-1919. (doi:10.1210/me.2002-0054)

Bianco P \& Robey PG 2004 Skeletal stem cells. In Handbook of Adult and Fetal Stem Cells, pp 415-424. Ed RP Lanza. San Diego: Academic Press.

Bianco P, Costantini M, Dearden LC \& Bonucci E 1988 Alkaline phosphatase positive precursors of adipocytes in the human bone marrow. British Journal of Haematology 68 401-403. (doi:10.1111/ j.1365-2141.1988.tb04225.x)

Bianco P, Kuznetsov SA, Riminucci M, Fisher LW, Spiegel AM \& Robey PG 1998 Reproduction of human fibrous dysplasia of bone in immunocompromised mice by transplanted mosaics of normal and Gsalpha-mutated skeletal progenitor cells. Journal of Clinical Investigation 101 1737-1744. (doi:10.1172/JCI2361)

Bianco P, Riminucci M, Majolagbe A, Kuznetsov SA, Collins MT, Mankani MH, Corsi A, Bone HG, Wientroub S, Spiegel AM et al. 2000 Mutations of the GNAS1 gene, stromal cell dysfunction, and osteomalacic changes in non-McCune-Albright fibrous dysplasia of bone. Journal of Bone and Mineral Research 15 120-128. (doi:10.1359/ jbmr.2000.15.1.120)

Bianco P, Robey PG \& Wientroub S 2003 Fibrous dysplasia. In Pediatric Bone, pp 509-539. Eds FH Glorieux, J Pettifor \& H Juppner. New York, NY: Elsevier Academic Press.

Bianco P, Kuznetsov SA, Riminucci M \& Gehron Robey P 2006 Postnatal skeletal stem cells. Methods in Enzymology 419 117-148. (doi:10.1016/S0076-6879(06) 19006-0)

Bianco P, Robey PG \& Simmons PJ 2008 Mesenchymal stem cells: revisiting history, concepts, and assays. Cell Stem Cell 2 313-319. (doi:10.1016/j.stem.2008.03.002)

Bourne HR, Landis CA \& Masters SB 1989 Hydrolysis of GTP by the alpha-chain of Gs and other GTP binding proteins. Proteins 6 222-230. (doi:10.1002/prot.340060304)

Caplan AI 1991 Mesenchymal stem cells. Journal of Orthopaedic Research 9 641-650. (doi:10.1002/jor.1100090504)

Constancia M, Pickard B, Kelsey G \& Reik W 1998 Imprinting mechanisms. Genome Research 8 881-900. (doi:10.1101/gr.8.9.881)

Corsi A, Collins MT, Riminucci M, Howell PG, Boyde A, Robey PG \& Bianco P 2003 Osteomalacic and hyperparathyroid changes in fibrous dysplasia of bone: core biopsy studies and clinical correlations. Journal of Bone and Mineral Research 18 1235-1246. (doi:10.1359/jbmr.2003.18.7.1235)

Dachille RD, Goldberg JS, Wexler ID \& Shons AR 1990 Fibrous dysplasia-induced hypocalcemia/rickets. Journal of Oral and Maxillofacial Surgery 48 1319-1322. (doi:10.1016/0278-2391(90)90491-J)

Dent CE \& Gertner JM 1976 Hypophosphataemic osteomalacia in fibrous dysplasia. Quarterly Journal of Medicine 45 411-420.

Feng JQ, Ward LM, Liu S, Lu Y, Xie Y, Yuan B, Yu X, Rauch F, Davis SI, Zhang S et al. 2006 Loss of DMP1 causes rickets and osteomalacia and identifies a role for osteocytes in mineral metabolism. Nature Genetics 38 1310-1315. (doi:10.1038/ng1905)

Freson K, Jaeken J, Van Helvoirt M, de Zegher F, Wittevrongel C, Thys C, Hoylaerts MF, Vermylen J \& Van Geet C 2003 Functional polymorphisms in the paternally expressed XLalphas and its cofactor ALEX decrease their mutual interaction and enhance receptor-mediated cAMP formation. Human Molecular Genetics 12 1121-1130. (doi:10.1093/hmg/ddg130) 
Frey UH, Nuckel H, Dobrev D, Manthey I, Sandalcioglu IE, Eisenhardt A, Worm K, Hauner H \& Siffert W 2005 Quantification of G protein Gaalphas subunit splice variants in different human tissues and cells using pyrosequencing. Gene Expression 12 69-81. (doi:10.3727/ 000000005783992124)

Friedenstein AJ, Chailakhjan RK \& Lalykina KS 1970 The development of fibroblast colonies in monolayer cultures of guinea-pig bone marrow and spleen cells. Cell and Tissue Kinetics 3 393-403. (doi:10.1111/j.1365-2184.1970.tb00347.x)

Friedenstein AJ, Chailakhyan RK, Latsinik NV, Panasyuk AF \& Keiliss-Borok IV 1974 Stromal cells responsible for transferring the microenvironment of the hemopoietic tissues. Cloning in vitro and retransplantation in vivo. Transplantation 17 331-340. (doi:10.1097/ 00007890-197404000-00001)

Friedenstein AJ, Chailakhyan RK \& Gerasimov UV 1987 Bone marrow osteogenic stem cells: in vitro cultivation and transplantation in diffusion chambers. Cell and Tissue Kinetics 20 263-272. (doi:10.1111/j.1365-2184.1987.tb01309.x)

Germain-Lee EL, Ding CL, Deng Z, Crane JL, Saji M, Ringel MD \& Levine MA 2002 Paternal imprinting of Galpha(s) in the human thyroid as the basis of TSH resistance in pseudohypoparathyroidism type 1a. Biochemical and Biophysical Research Communications 296 67-72. (doi:10.1016/S0006-291X(02)00833-1)

Hayward BE, Kamiya M, Strain L, Moran V, Campbell R, Hayashizaki Y \& Bonthron DT 1998a The human GNAS1 gene is imprinted and encodes distinct paternally and biallelically expressed $\mathrm{G}$ proteins. PNAS 95 10038-10043. (doi:10.1073/pnas.95.17.10038)

Hayward BE, Moran V, Strain L \& Bonthron DT $1998 b$ Bidirectional imprinting of a single gene: GNAS1 encodes maternally, paternally, and biallelically derived proteins. PNAS 95 15475-15480. (doi:10. 1073/pnas.95.26.15475)

Hayward BE, Barlier A, Korbonits M, Grossman AB, Jacquet P, Enjalbert A \& Bonthron DT 2001 Imprinting of the G(s)alpha gene GNAS1 in the pathogenesis of acromegaly. Journal of Clinical Investigation 107 R31-R36. (doi:10.1172/JCI11887)

Henschen F \& Fallvon H 1926 Ostitis fibrosa mit multiplen tumores in der umgebenden muskulature. Verhandlungen der Deutschen Gesellschaft für Pathologie 21 93-97.

Holmes R, Williamson C, Peters J, Denny P \& Wells C 2003 A comprehensive transcript map of the mouse Gnas imprinted complex. Genome Research 13 1410-1415. (doi:10.1101/gr.955503)

Ihnatovych I, Hejnova L, Kostrnova A, Mares P, Svoboda P \& Novotny J 2001 Maturation of rat brain is accompanied by differential expression of the long and short splice variants of $\mathrm{G}(\mathrm{s})$ alpha protein: identification of cytosolic forms of $\mathrm{G}(\mathrm{s})$ alpha. Journal of Neurochemistry 79 88-97. (doi:10.1046/j.1471-4159.2001.00544.x)

Ischia R, Lovisetti-Scamihorn P, Hogue-Angeletti R, Wolkersdorfer M, Winkler H \& Fischer-Colbrie R 1997 Molecular cloning and characterization of NESP55, a novel chromogranin-like precursor of a peptide with 5-HT1B receptor antagonist activity. Journal of Biological Chemistry 272 11657-11662. (doi:10.1074/jbc.272.17. 11657)

Jonsson KB, Zahradnik R, Larsson T, White KE, Sugimoto T, Imanishi Y, Yamamoto T, Hampson G, Koshiyama H, Ljunggren O et al. 2003 Fibroblast growth factor 23 in oncogenic osteomalacia and X-linked hypophosphatemia. New England Journal of Medicine 348 1656-1663. (doi:10.1056/NEJMoa020881)

Kehlenbach RH, Matthey J \& Huttner WB 1994 XL alpha s is a new type of G protein. Nature 372 804-809. (doi:10.1038/372804a0)

Klemke M, Pasolli HA, Kehlenbach RH, Offermanns S, Schultz G \& Huttner WB 2000 Characterization of the extra-large G protein alpha-subunit XLalphas. II. Signal transduction properties. Journal of Biological Chemistry 275 33633-33640. (doi:10.1074/jbc. M006594200)

Klemke M, Kehlenbach RH \& Huttner WB 2001 Two overlapping reading frames in a single exon encode interacting proteins - a novel way of gene usage. EMBO Journal 20 3849-3860. (doi:10.1093/ emboj/20.14.3849)
Kobayashi K, Imanishi Y, Koshiyama H, Miyauchi A, Wakasa K, Kawata T, Goto H, Ohashi H, Koyano HM, Mochizuki R et al. 2006 Expression of FGF23 is correlated with serum phosphate level in isolated fibrous dysplasia. Life Sciences 78 2295-2301. (doi:10.1016/j.lfs.2005.09.052)

Kuznetsov SA, Cherman N, Riminucci M, Collins MT, Robey PG \& Bianco P 2008 Age-dependent demise of GNAS-mutated skeletal stem cells and "normalization" of fibrous dysplasia of bone. Journal of Bone and Mineral Research 23 1731-1740. (doi:10.1359/ jbmr.080609)

Kvapil P, Novotny J, Svoboda P \& Ransnas LA 1994 The short and long forms of the alpha subunit of the stimulatory guanine-nucleotidebinding protein are unequally redistributed during $(-)$-isoproterenol-mediated desensitization of intact S49 lymphoma cells. European Journal of Biochemistry 226 193-199. (doi:10.1111/ j.1432-1033.1994.tb20041.x)

Linglart A, Mahon MJ, Kerachian MA, Berlach DM, Hendy GN, Juppner H \& Bastepe M 2006 Coding GNAS mutations leading to hormone resistance impair in vitro agonist- and cholera toxininduced adenosine cyclic $3^{\prime}, 5^{\prime}$-monophosphate formation mediated by human XLalphas. Endocrinology 147 2253-2262. (doi:10.1210/en.2005-1487)

Liu J, Chen M, Deng C, Bourc'his D, Nealon JG, Erlichman B, Bestor TH \& Weinstein LS 2005 Identification of the control region for tissue-specific imprinting of the stimulatory $\mathrm{G}$ protein alpha-subunit. PNAS 102 5513-5518. (doi:10.1073/pnas. 0408262102)

Mantovani G, Ballare E, Giammona E, Beck-Peccoz P \& Spada A 2002 The gsalpha gene: predominant maternal origin of transcription in human thyroid gland and gonads. Journal of Clinical Endocrinology and Metabolism 87 4736-4740. (doi:10.1210/ jc.2002-020183)

Mantovani G, Bondioni S, Locatelli M, Pedroni C, Lania AG, Ferrante E, Filopanti M, Beck-Peccoz P \& Spada A 2004 Biallelic expression of the Gsalpha gene in human bone and adipose tissue. Journal of Clinical Endocrinology and Metabolism 89 6316-6319. (doi:10.1210/jc.2004-0558)

Michienzi S, Cherman N, Holmbeck K, Funari A, Collins MT, Bianco P, Robey PG \& Riminucci M 2007 GNAS transcripts in skeletal progenitors: evidence for random asymmetric allelic expression of Gs alpha. Human Molecular Genetics 16 1921-1930. (doi:10.1093/ $\mathrm{hmg} / \mathrm{ddm} 139$ )

Novotny J \& Svoboda P 1998 The long (Gs(alpha)-L) and short (Gs(alpha)-S) variants of the stimulatory guanine nucleotidebinding protein. Do they behave in an identical way? Journal of Molecular Endocrinology 20 163-173. (doi:10.1677/jme.0.0200163)

Owen M \& Friedenstein AJ 1988 Stromal stem cells: marrow-derived osteogenic precursors. Ciba Foundation Symposia 136 42-60.

Pasolli HA, Klemke M, Kehlenbach RH, Wang Y \& Huttner WB 2000 Characterization of the extra-large $\mathrm{G}$ protein alpha-subunit XLalphas. I. Tissue distribution and subcellular localization. Journal of Biological Chemistry 275 33622-33632. (doi:10.1074/ jbc.M001335200)

Peters J, Wroe SF, Wells CA, Miller HJ, Bodle D, Beechey CV, Williamson CM \& Kelsey G 1999 A cluster of oppositely imprinted transcripts at the Gnas locus in the distal imprinting region of mouse chromosome 2. PNAS 96 3830-3835. (doi:10. $1073 /$ pnas.96.7.3830)

Piersanti S, Remoli C, Saggio I, Funari A, Michienzi S, Sacchetti B, Robey PG, Riminucci M \& Bianco P 2010 Transfer, analysis, and reversion of the fibrous dysplasia cellular phenotype in human skeletal progenitors. Journal of Bone and Mineral Research 25 1103-1116. (doi:10.1359/jbmr.091036)

Pittenger MF, Mackay AM, Beck SC, Jaiswal RK, Douglas R, Mosca JD, Moorman MA, Simonetti DW, Craig S \& Marshak DR 1999 Multilineage potential of adult human mesenchymal stem cells. Science 284 143-147. (doi:10.1126/science.284.5411.143) 
Plagge A, Gordon E, Dean W, Boiani R, Cinti S, Peters J \& Kelsey G 2004 The imprinted signaling protein XL alpha $s$ is required for postnatal adaptation to feeding. Nature Genetics 36 818-826. (doi:10.1038/ng1397)

Quarles LD 2003 FGF23, PHEX, and MEPE regulation of phosphate homeostasis and skeletal mineralization. American Journal of Physiology. Endocrinology and Metabolism 285 E1-E9. (doi:10.1152/ ajpendo.00016.2003)

Rao VV, Schnittger S \& Hansmann I 1991 G protein Gs alpha (GNAS 1), the probable candidate gene for Albright hereditary osteodystrophy, is assigned to human chromosome 20q12-q13.2. Genomics 10 257-261. (doi:10.1016/ 0888-7543(91)90508-C)

Reik W \& Walter J 2001 Genomic imprinting: parental influence on the genome. Nature Reviews. Genetics 2 21-32. (doi:10.1038/ 35047554)

Riminucci M, Fisher LW, Shenker A, Spiegel AM, Bianco P \& Gehron Robey P 1997 Fibrous dysplasia of bone in the McCune-Albright syndrome: abnormalities in bone formation. American Journal of Pathology 151 1587-1600.

Riminucci M, Liu B, Corsi A, Shenker A, Spiegel AM, Robey PG \& Bianco P 1999 The histopathology of fibrous dysplasia of bone in patients with activating mutations of the Gs alpha gene: site-specific patterns and recurrent histological hallmarks. Journal of Pathology 187 249-258. (doi:10.1002/(SICI) 1096-9896(199901) 187:2 $<249:$ :AID-PATH222>3.0.CO;2-J)

Riminucci M, Collins MT, Fedarko NS, Cherman N, Corsi A, White KE, Waguespack S, Gupta A, Hannon T, Econs MJ et al. 2003a FGF-23 in fibrous dysplasia of bone and its relationship to renal phosphate wasting. Journal of Clinical Investigation 112 683-692. (doi:10.1172/ JCI18399)

Riminucci M, Kuznetsov SA, Cherman N, Corsi A, Bianco P \& Gehron Robey P $2003 b$ Osteoclastogenesis in fibrous dysplasia of bone: in situ and in vitro analysis of IL-6 expression. Bone 33 434-442. (doi:10.1016/S8756-3282(03)00064-4)

Riminucci M, Saggio I, Robey PG \& Bianco P 2006 Fibrous dysplasia as a stem cell disease. Journal of Bone and Mineral Research 21 (Supplement 2) P125-P131. (doi:10.1359/jbmr.06s224)

Ryan WG, Nibbe AF, Schwartz TB \& Ray RD 1968 Fibrous dysplasia of bone with vitamin D resistant rickets: a case study. Metabolism 17 988-998. (doi:10.1016/0026-0495(68)90004-8)

Sacchetti B, Funari A, Michienzi S, Di Cesare S, Piersanti S, Saggio I, Tagliafico E, Ferrari S, Robey PG, Riminucci M et al. 2007 Selfrenewing osteoprogenitors in bone marrow sinusoids can organize a hematopoietic microenvironment. Cell 131 324-336. (doi:10. 1016/j.cell.2007.08.025)

Schwindinger WF, Francomano CA \& Levine MA 1992

Identification of a mutation in the gene encoding the alpha subunit of the stimulatory $\mathrm{G}$ protein of adenylyl cyclase in McCune-Albright syndrome. PNAS 89 5152-5156. (doi:10.1073/ pnas.89.11.5152)

Shimada T, Mizutani S, Muto T, Yoneya T, Hino R, Takeda S, Takeuchi Y, Fujita T, Fukumoto S \& Yamashita T 2001
Cloning and characterization of FGF23 as a causative factor of tumor-induced osteomalacia. PNAS 98 6500-6505. (doi:10.1073/ pnas.101545198)

Stanton RP, Hobson GM, Montgomery BE, Moses PA, Smith-Kirwin SM \& Funanage VL 1999 Glucocorticoids decrease interleukin-6 levels and induce mineralization of cultured osteogenic cells from children with fibrous dysplasia. Journal of Bone and Mineral Research 14 1104-1114. (doi:10.1359/jbmr.1999.14.7.1104)

Tavassoli M \& Crosby WH 1968 Transplantation of marrow to extramedullary sites. Science 161 54-56. (doi:10.1126/science.161. 3836.54)

Unson CG, Wu CR, Sakmar TP \& Merrifield RB 2000 Selective stabilization of the high affinity binding conformation of glucagon receptor by the long splice variant of Galpha(s). Journal of Biological Chemistry 275 21631-21638. (doi:10.1074/jbc.M002093200)

van der Vuurst H, Hendriks M, Lapetina EG, van Willigen G \& Akkerman JW 1998 Maturation of megakaryoblastic cells is accompanied by upregulation of G(s)alpha-L subtype and increased cAMP accumulation. Thrombosis and Haemostasis 79 1014-1020.

Weinstein LS, Shenker A, Gejman PV, Merino MJ, Friedman E \& Spiegel AM 1991 Activating mutations of the stimulatory $G$ protein in the McCune-Albright syndrome. New England Journal of Medicine 325 1688-1695. (doi:10.1056/NEJM199112123252403)

Weiss L 1976 The hematopoietic microenvironment of the bone marrow: an ultrastructural study of the stroma in rats. The Anatomical Record 186 161-184. (doi:10.1002/ar.1091860204)

Wenzel-Seifert K, Kelley MT, Buschauer A \& Seifert R 2001 Similar apparent constitutive activity of human histamine $\mathrm{H}(2)$-receptor fused to long and short splice variants of $\mathrm{G}$ (salpha). Journal of Pharmacology and Experimental Therapeutics 299 1013-1020.

Westen H \& Bainton DF 1979 Association of alkaline-phosphatasepositive reticulum cells in bone marrow with granulocytic precursors. Journal of Experimental Medicine 150 919-937.

Wroe SF, Kelsey G, Skinner JA, Bodle D, Ball ST, Beechey CV, Peters J \& Williamson CM 2000 An imprinted transcript, antisense to Nesp, adds complexity to the cluster of imprinted genes at the mouse Gnas locus. PNAS 97 3342-3346. (doi:10.1073/pnas.050015397)

Yan H, Yuan W, Velculescu VE, Vogelstein B \& Kinzler KW 2002 Allelic variation in human gene expression. Science 297 1143. (doi:10. 1126 /science.1072545)

Yu X \& White KE 2005 FGF23 and disorders of phosphate homeostasis. Cytokine $\mathcal{E}$ Growth Factor Reviews 16 221-232. (doi:10.1016/j.cytogfr. 2005.01.002)

Received in final form 6 September 2010 Accepted 14 September 2010

Made available online as an Accepted Preprint 14 September 2010 